\title{
Treadmill exercise improves behavioral outcomes and spatial learning memory through up-regulation of reelin signaling pathway in autistic rats
}

\author{
Tae-Beom Seo' , Han-Sam Cho², Mal-Soon Shin², Chang-Ju Kim², Eun-Sang Ji³ , Seung-Soo Baek,** \\ 'Department of Biochemistry, Division of Sports Science \& Engineering, Korea Institute of Sports Science, Seoul, Korea \\ ${ }^{2}$ Department of Physiology, College of Medicine, Kyung Hee University, Seoul, Korea \\ ${ }^{3}$ Department of Sport \& Health Science, College of Natural Science, Sangmyung University, Seoul, Korea
}

Autism is a complex neurodevelopmental disability with impairments of social interaction and communication, and repetitive behavior. Reelin is an extracellular glycoprotein that is essential for neuronal migration and brain development. Neuroprotective effects of exercise on various brain insults are well documented, however, the effects of exercise on autism in relation with reelin expression are not clarified. In the present study, we investigated the effects of treadmill exercise on the functional recovery and on the expressions of reelin and its downstream molecules, phosphatidylinositol-3-kinase (PI3K), phosphorylated Akt (p-Akt), phosphorylated extracellular signal-regulated protein kinase 1 and 2 (p-ERK1/2), using autistic rats. For the induction of autism-like animal model, $400 \mathrm{mg} / \mathrm{kg}$ valproic acid was subcutaneously injected into the rats on the postnatal day 14 . The rat in the treadmill exercise groups were forced to run on a treadmill for 30 min once a day, five times a week for 4 weeks, starting postnatal day 28. To investigate autism-like behaviors and memory deficit, open field, social interaction, and radial 8-arm maze were performed. Immunohistochemistry and western blotting were conducted. In the present results, treadmill exercise alleviated aggressive tendency and improved correct decision in the spatial learning memory in the autistic rats. Treadmill exercise increased neurogenesis and the expressions of reelin and its down-stream molecules, PI3K, p-Akt, and p-ERK1/2, in the hippocampus of the autistic rats. The present study showed that treadmill exercise ameliorated aggressive behavior and improved spatial learning memory through activation of reeling signaling pathway in the valproic acid-induced autistic rats.

Keywords: Autism, Valproic acid, Treadmill exercise, Reelin, Hippocampus, Neurogenesis

\section{INTRODUCTION}

Autism is a complex neurodevelopmental disability with a variety of symptoms including impairments of social interaction and communication, and repetitive behavior (Fatemi et al., 2005; Vernazza-Martin et al., 2005). Autism is generally diagnosed between the ages of six months and three years old (Rogers, 2009), and it has been hypothesized that autism's symptoms may be resulted from the maturation-related histological alterations in many areas of brain, and these changes are closely associated with dysregulation of biochemical molecules expressed in the autistic brains
(Penn, 2006). Since autism was first recognized as a disorder in 1943 , speculation about its etiology has ranged from biological to psychological and back again. However unknown causes account for $80-90 \%$ of cases.

Apoptosis is a form of cell death that constitutes part of a common mechanism in cell replacement, tissue remodeling, and removal of damaged cells (Thompson, 1995). Apoptosis has two main pathways (the extrinsic and intrinsic pathways). A class of cysteine proteases, such as caspase- 8 , caspase- 9 , and caspase- 3 , is commonly involved in these pathways (Nuñez et al., 1998). Of these, caspase- 3 is the most widely studied member of the caspase
${ }^{*}$ Corresponding author: Seung-Soo Baek

Department of Sport \& Health Science, College of Natural Science, Sangmyung

University, 20 Hongjimun 2-gil, Jongno-gu, Seoul 110-743, Korea

Tel: +82-2-2287-5133, Fax: +82-2-2287-0075, E-mail: ssoop@smu.ac.kr

Received: February 5, 2013/ Revised: February 28, 2013/ Accepted: March 13, 2013
This is an Open Access article distributed under the terms of the Creative Commons Attribution Non-Commercial License (http://creativecommons.org/licenses/by-nc/3.0/) which permits unrestricted non-commercial use, distribution, and reproduction in any medium, provided the original work is properly cited. 
family and it is one of key executors of apoptosis (Cohen, 1997). Excessive neuronal apoptosis contributes to dysfunction of the central nervous system (Baek et al., 2012; Kuhn et al., 2005).

Reelin is a large secreted extracellular matrix glycoprotein that regulates migration and positioning of neurons as well as synaptic plasticity in the developmental brain (Fatemi, 2005; Fatemi et al., 2001). Its activity is regulated by a signaling transduction pathway binding to the two members of very low density lipoprotein receptor (VLDL) and the apolipoprotein E receptor s (ApoER2). VLDL and ApoER2 phosphorylate intracellular adaptor protein Disabled-1 (Dab-1), which facilitates Src-tyrosine kinase family. These changes activate specific molecules such as phosphatidylinositol-3-kinase (PI3K) and protein kinase B (Akt), and extracellular signal-regulated protein kinase 1 and 2 (ERK1/2), then lead to inhibition of neuronal apoptosis in the brain (Beffert et al., 2002, 2005). Fatemi et al. (2001) reported the deficits in the brain levels of reelin mRNA and protein in the subjects with schizophrenia, major depression, and autism.

Exercise enhances learning ability and memory functions, protects from neurodegeneration, delays age-related cognitive decline, and alleviates symptoms of the developmental and neuropsychiatric disorders (Cotman et al., 2007; Kim et al., 2010, 2011; Seo et al., 2013). Neuroprotective effects of exercise on various brain insults are well documented (Kim et al., 2011; Lang et al., 2010; Petrus et al., 2008), however, the effects of exercise on autism in relation with reelin expression are not clarified. In the present study, we investigated the effects of treadmill exercise on the functional recovery and on the expressions of reelin and its downstream molecules, PI3K, phosphorylated Akt (p-Akt), phosphorylated ERK1/2 (p-ERK1/2), using valproic acid (VPA)-induced autistic rats.

\section{MATERIALS AND METHODS}

\section{Experimental animals and treatments}

Male Sprague-Dawley rats, weighing $26 \pm 8 \mathrm{~g}$ (2 weeks of age) were used for the experiment. The experimental procedures were performed in accordance with the animal care guidelines of the National Institutes of Health (NIH) and the Korean Academy of Medical Sciences. The rats were housed under the controlled temperature $\left(20 \pm 2^{\circ} \mathrm{C}\right)$, humidity $(60 \%)$, and the lighting (08:0020:00 h) conditions. Food and water were made available ad libitum. The animals were randomly assigned to each of four groups ( $n=15$ in each group): the control group, the treadmill exercise group, the VPA-treated group, and the VPA-treated and tread- mill exercise group.

For the induction of autism-like animal model, $400 \mathrm{mg} / \mathrm{kg}$ valproic acid (Sigma Chemical Company, St. Lois, MO, USA) dissolved in saline at a concentration of $0.1 \mathrm{~mL} / \mathrm{kg}$ was subcutaneously injected into the rat pups on the postnatal day 14, according to the previous described method (Wagner et al., 2006). Day of birth was recorded as day 0 , and all rats were labeled for individual identification. The rats in the control groups received subcutaneous injection of saline in the same volume and on the same schedule.

After starting of treadmill exercise, 5-bromo- 2 -deoxyuridine (BrdU) (Sigma Chemical Company) administrated to all animals via intraperitoneal injection $(50 \mathrm{mg} / \mathrm{kg}$ in saline), once daily for 3 times during a week. The animals were sacrificed immediately after finishing behavior tests.

\section{Treadmill exercise protocol}

The rat in the treadmill exercise groups were forced to run on a treadmill for 30 min once a day, five times a week for 4 weeks, starting postnatal day 28. Exercise load for the exercise groups consisted of running at a speed of 2 meters $/ \mathrm{min}$ for the first $5 \mathrm{~min}$, at a speed of $5 \mathrm{~m} / \mathrm{min}$ for the next $5 \mathrm{~min}$, and then at a speed of 8 $\mathrm{m} / \mathrm{min}$ for the last $20 \mathrm{~min}$, with the $0^{\circ}$ inclination.

\section{Open field test}

For open field test, the animals were randomly assigned to an order of testing and placed in a white square open field arena (100 $\mathrm{cm} \times 100 \mathrm{~cm}$ ) made of wood. As previously reported (Kim et al., 2011), it was enclosed with 40-cm high walls and placed under strong illumination (200 lux). The arena was divided into 25 squares (each square is $20 \times 20 \mathrm{~cm}$ ), defined as 9 central and 16 peripheral squares. The animal was placed in the center of the arena and left free to explore the environment for $1 \mathrm{~min}$. After that time, the numbers of squares that the rat crossed were recorded for $5 \mathrm{~min}$.

\section{Social interaction test}

The social interaction test was conducted in a $120 \times 120 \times 60$ $\mathrm{cm}$ black wooden arena illuminated by a $40 \mathrm{~W}$ red lamp. Ageand treatment-matched pairs of rats with approximately equal body weight, but from different home cages, were placed together in the arena for $20 \mathrm{~min}$. Social behaviors include: (1) following/ chasing: one rat following the other within a distance of two bodylengths, (2) anogenital interactions, (3) adjacent interactions: including play-fighting, climbing over/under, and adjacent lying, (4) head-to-head interactions, and (5) total social interaction: time 
spent in all of the above categories. The apparatus was cleaned with $50 \%$ ethanol between test sessions.

\section{Radial 8-arm maze test}

Spatial learning memory was tested using a radial 8-arm maze apparatus, as the previously described method (Kim et al., 2010). The radial 8-arm maze apparatus consisted of a central octagonal plate $(30 \mathrm{~cm}$ in diameter) and radiating eight arms $(50 \mathrm{~cm}$ in length and $10 \mathrm{~cm}$ in width). The apparatus was placed $1 \mathrm{~m}$ above the floor. A small receptacle filled with water $(3 \mathrm{~cm}$ in diameter and 1 $\mathrm{cm}$ in depth) was located at the end of the arms. The rats were trained three times before the spatial learning test. In the training sessions, the rats deprived of water for $24 \mathrm{~h}$ were allowed to explore the water and to drink for $5 \mathrm{~min}$. The time spent in seeking water at the end of the arms was counted. The test was terminated when a rat found water in all eight arms or over 6 min elapsed. The number of correct choice before the first error was counted. Re-entering to the previously visited arms was counted as the error.

\section{Tissue preparation}

The experimental animals were fully anesthetized using Zoletil $50^{\circledR}(10 \mathrm{mg} / \mathrm{kg}$, i.p.; Vibac Laboratories, Carros, France), transcardially perfused with $50 \mathrm{mM}$ phosphate-buffered saline (PBS), and fixed with a freshly prepared solution consisting of $4 \%$ paraformaldehyde in $100 \mathrm{mM}$ phosphate buffer ( $\mathrm{PB}, \mathrm{pH}$ 7.4). Brains were dissected, post-fixed in the same fixative overnight, and transferred to $30 \%$ sucrose for cryoprotection. Sagittal sections of 40 $\mu \mathrm{m}$ thickness in each section of cerebellum were made with a freezing microtome (Lieca, Nussloch, Germany). The sections were finally mounted onto gelatin-coated slides. The slides were air-dried overnight at room temperature, and the coverslips were mounted using Permount ${ }^{\circledR}$.

\section{BrdU immunohistochemistry}

For the detection of newly generated cells in the hippocampal dentate gyrus, BrdU-specific immunohistochemistry was performed according to a previously described method (Baek et al., 2012). In brief, the sections were permeabilized by incubating them in $0.5 \%$ Triton X-100 in PBS for 20 min, then they were pre-treated in $50 \%$ formamide- $2 \times$ standard saline citrate (SSC) at $65^{\circ} \mathrm{C}$ for $2 \mathrm{~h}$, denaturated in $2 \mathrm{~N} \mathrm{HCl}$ at $37^{\circ} \mathrm{C}$ for $30 \mathrm{~min}$, and they were rinsed twice in $100 \mathrm{mM}$ sodium borate ( $\mathrm{pH}$ 8.5). Afterwards, the sections were incubated overnight at $4^{\circ} \mathrm{C}$ with $\mathrm{BrdU}$ specific mouse monoclonal antibody (1:600; Roche, Mannheim, Germany). The sections were then washed three times with PBS and incubated for $1 \mathrm{~h}$ with the biotinylated mouse secondary antibody (1:200; Vector Laboratories, Burlingame, CA, USA). Then, the sections were incubated for another $1 \mathrm{~h}$ with avidin-peroxidase complex (1:100; Vector Laboratories). For visualization, the sections were incubated for $5 \mathrm{~min}$ in $50 \mathrm{mM}$ Tris- $\mathrm{HCl}(\mathrm{pH}$ 7.6) containing $0.02 \% 3,3^{\prime}$-diaminobenzidine (DAB), $40 \mathrm{mg} / \mathrm{ml}$ nickel chloride, and $0.03 \%$ hydrogen peroxide. The slides were air-dried overnight at room temperature, and the coverslips were mounted using Permount ${ }^{\circledR}$ (Fisher Scientific, New Jersey, NJ, USA).

\section{Caspase-3 immunohistochemistry}

Caspase-3 immunohistochemistry was performed, according to a previously described method (Kim et al., 2010). In brief, the sections were incubated overnight with mouse anti-caspase- 3 antibody (1:500; Santa Cruz Biotechnology, Santa Cruz, CA, USA) and then they were incubated for another $1 \mathrm{~h}$ with the biotinylated mouse secondary antibody. The bound secondary antibody was then amplified using a Vector Elite ABC kit ${ }^{\circledR}$ (1:100; Vector Laboratories). The antibody-biotin-avidin-peroxidase complex was visualized using $0.03 \% \mathrm{DAB}$. The sections were finally mounted onto gelatin-coated slides. The slides were air-dried overnight at room temperature, and the coverslips were mounted using Permount $^{\circledast}$ ( Fisher Scientific).

\section{Western blot analysis}

Western blotting was conducted a previously described method (Kim et al., 2010). Tissue samples harvested from the hippocampus were lysed in the protein lysis buffer containing $50 \mathrm{mM} \mathrm{HE}$ -

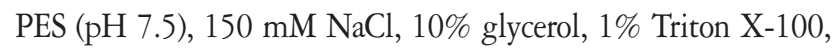
$1.5 \mathrm{mM}$ magnesium chloride hexahydrate, $1 \mathrm{mM}$ phenylmethylsulfonyl fluoride (PMSF), $2 \mathrm{mg} / \mathrm{mL}$ leupeptin, $1 \mathrm{mg} / \mathrm{mL}$ pepstatin, $1 \mathrm{mM}$ sodium ortho vanadate, and $100 \mathrm{mM}$ sodium floride. Protein concentration was measured using a Bio-Rad colorimetric protein assay kit (Hercules, CA, USA). Protein of $40 \mu \mathrm{g}$ was separated on SDS-polyacrylamide gels and transferred onto a nitrocellulose membrane (Schleicher \& Schuell GmbH, Dassel, Germany). Mouse anti-reelin antibody (1:1,000; Millipore Corporation, Billerica, MA, USA), mouse anti-PI3K antibody (1:1,000; Santa Cruz Biotechnology), rabbit anti-p-Akt antibody (1:2,000; Cell Signaling Technology, Beverly, MA, USA), rabbit anti-total Akt antibody (1:1,000; Cell Signaling Technology), mouse anti-pERK1/2 antibody (1:1,000; Santa Cruz Biotechnology), and rabbit anti-total ERK1/2 antibody (1:2,000; Cell Signaling Technology) used as primary antibodies. Horseradish peroxidase-conjugated anti-mouse antibody (1:3,000; Santa Cruz Biotechnology) 
for actin, and horseradish peroxidase-conjugated anti-rabbit antibody (1:4,000; Vector Laboratories) or horseradish peroxidase-conjugated anti-mouse antibody (1:3000; Vector Laboratories) used as secondary antibodies. Band detection was performed using as enhanced chemiluminescence (ECL) detection system (Amersham Pharmacia Biothech GmbH, Freiburg, Germany).

\section{Statistical analysis}

The numbers of caspase-3-positive and BrdU-positive cells in the hippocampal dentate gyrus were counted using confocal laser-scanning microscopy with LSM 510 META (Carl Zeiss, Oberkochen, Germany). The numbers of caspase-3-positive and BrdUpositive cells in the hippocampal dentate gyrus were expressed as the number of cells per $\mathrm{mm}^{2}$ of the cross sectional area of the granular layer. The final amount of western blot product for protein expression was calculated densitometrically using Imaging-Pro ${ }^{\circledR}$ Plus (Media Cybernetics Inc., Silver Spring, MD, USA).

All data were analyzed using the statistical software SPSS (version 18.0). The data are expressed as the mean \pm standard error of the mean (SEM). For the comparison among the groups, one-way analysis of variance (ANOVA) and Duncan's post-hoc test were performed and differences were considered statistically significant at $P<0.05$.

\section{RESULT}

\section{Expression of caspase-3 in the hippocampus one day after VPA treatment}

One day after VPA treatment, caspase-3 expression was detected using caspase- 3 immunohistocheistry. The number of caspase- 3 positive cells in the hippocampal dentate gyrus was $7.4 \pm 1.3$ in the control group and $48.7 \pm 3.1$ in the one day after VPA-treated group $(P<0.05)$. Many caspased-3-labeled cells were observed in the VPA-treated rats compared to the control group. The present results indicate that VPA injection induced apoptotic cell death in the hippocampus.

\section{Effect of treadmill exercise on the activity in the open field test and on the behaviors in the social interaction test}

The effect of treadmill exercise on the activity in the open field test is presented in Fig. 1A. The activity level was $85.1 \pm 7.4$ in the control group, $97.5 \pm 9.6$ in the control and treadmill exercise group, $53.6 \pm 10.4$ in the VPA-treated group, and $67.3 \pm 11.1$ in the VPA-treated and treadmill exercise group. The present results indicated that the activity in the VPA-treated group was decreas-
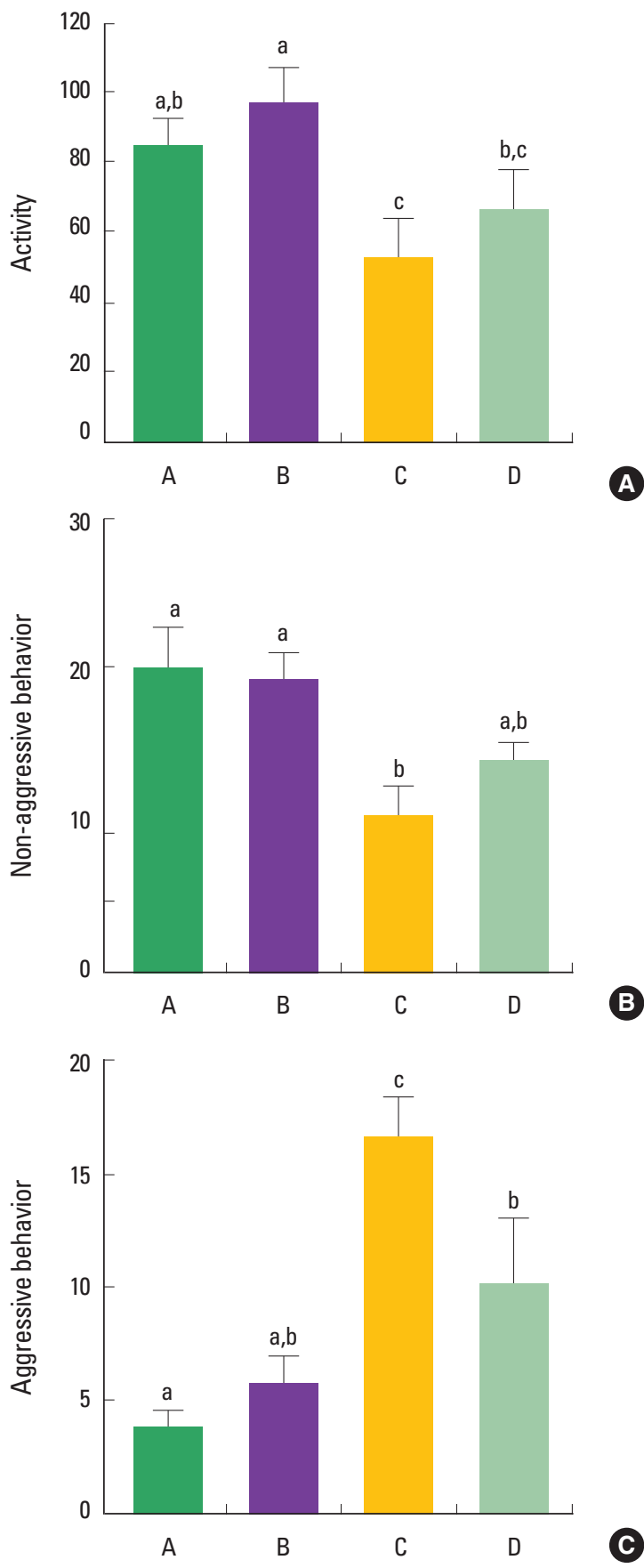

Fig. 1. Effect of treadmill exercise on the activity in the open field test and the behaviors in the social interaction test. (A) Open field test. (B) The number of non-aggressive behavior in social interaction test. (C) The number of aggressive behavior in social interaction test. (A) Control group, (B) control and exercise group, (C) valproic acid (VPA)-treated group, (D) VPA-treated and treadmill exercise group. The data are represented as the mean \pm SEM. Symbols $a, b, c$ represent statistical significance $(P<0.05)$ in each group.

ed compared to the control group $(P<0.05)$. However, treadmill exercise did not significantly increase the activity in the VPA-in- 
jected rats $(P>0.05)$.

The effect of treadmill exercise on the behaviors in the social interaction test is presented in Fig. 1B, C. The number of non-aggressive behavior was $20.0 \pm 2.7$ in the control group, 19.2 \pm 1.8 in the control and treadmill exercise group, 10.4 \pm 1.9 in the VPAtreated group, and $14.2 \pm 0.9$ in the VPA-treated and treadmill exercise group. The number of aggressive behavior was $3.8 \pm 0.7$ time in the control group, $5.8 \pm 1.1$ time in the control and treadmill exercise group, 16.8 \pm 1.6 time in the VPA-treated group, and 10.2 \pm 2.9 time in the VPA-treated and treadmill exercise group. The present results indicated that non-aggressive behavior was decreased and aggressive behavior was increased in the VPAtreated group compared to the control group $(P<0.05)$. Treadmill exercise did not enhance non-aggressive behavior $(P>0.05)$, however, treadmill exercise suppressed aggressive behavior in the VPA-injected rats $(P<0.05)$.

\section{Effect of treadmill exercise on the spatial learning memory in the radial 8-arm maze test}

The effect of treadmill exercise on spatial learning memory in the radial 8-arm maze test is presented in Fig. 2. The time taken to complete eight successful performances was $249.3 \pm 30.6 \mathrm{sec}$ in the control group, $194.9 \pm 15.4 \mathrm{sec}$ in the control and treadmill exercise group, $368.6 \pm 24.9 \mathrm{sec}$ in the VPA-treated group, 294.1 $\pm 47.2 \mathrm{sec}$ in the VPA-treated and treadmill exercise group. The number of correct choices to complete eight successful performances was $5.2 \pm 0.5$ in the control group, $7.2 \pm 0.1$ in the control and treadmill exercise group, $3.0 \pm 0.4$ in the VPA-treated group, and $4.7 \pm 1.9$ in the VPA-treated and treadmill exercise group. The number of error to complete eight successful performances was $4.6 \pm 0.5$ in the control group, $2.7 \pm 0.7$ in the control and treadmill exercise group, $6.0 \pm 1.4$ in the VPA-treated group, and $5.1 \pm 0.8$ in the VPA-treated and treadmill exercise group. The present result indicated that time and error number were increased and correct number was decreased in the VPA-treated group compared to the control group $(P<0.05)$. Treadmill exercise did not decrease time and error number $(P>0.05)$, however, treadmill exercise increased correct number in the VPA-injected rats $(P<0.05)$.

\section{Effect of treadmill exercise on the hippocampal neurogenesis}

The effect of treadmill exercise on the neurogenesis in the hippocampal dentate gyrus is presented in Fig. 3. The number of BrdU-positive cells in the hippocampal dentate gyrus was 198.5 \pm 8.8 in the control group, $214.1 \pm 6.9$ in the control and tread-
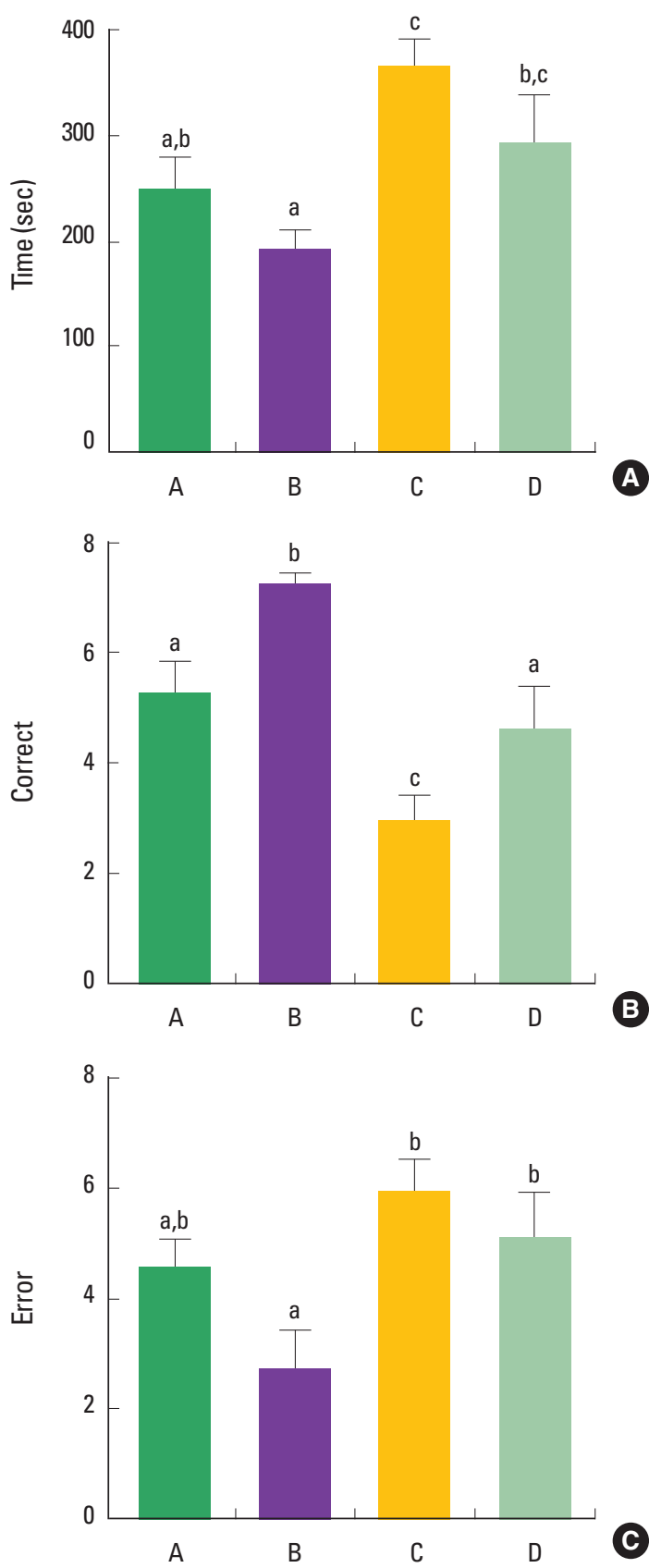

Fig. 2. Effect of treadmill exercise on the performance time, correct number, and error number in the radial 8-arm maze test. $(\mathrm{A})$ The time taken to complete eight successful performances. (B) The number of correct choices to complete eight successful performances. (C) The number of error responses to complete eight successful performances. (A) Control group, (B) control and exercise group, (C) valproic acid (VPA)-treated group, (D) VPA-treated and treadmill exercise group. The data are represented as the mean \pm SEM. Symbols $a, b, c$ represent statistical significance $(P<0.05)$ in each group.

mill exercise group, 62.6 \pm 5.4 in the VPA-treated group, and $102.3 \pm 4.6$ in the VPA-treated and treadmill exercise group. The 

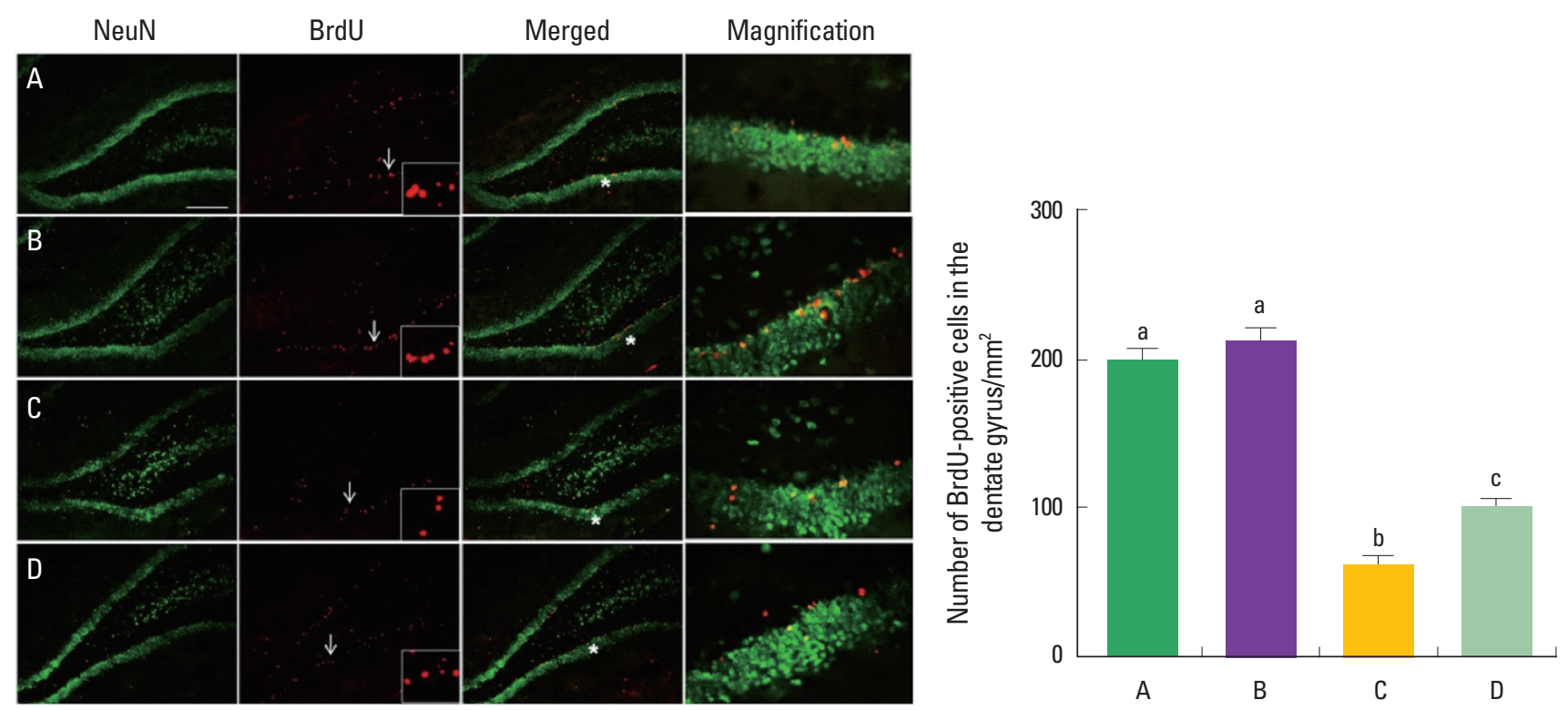

Fig. 3. Effect of treadmill exercise on the neurogenesis in the dentate gyrus of the hippocampus. (A) Photomicrographys of neuronal nuclei and 5-bromo-2'-deoxyuridine (BrdU)-positive cells. The scale bar represents $500 \mu \mathrm{m}$. (B) The number of BrdU-positive cells. (A) Control group, (B) control and exercise group, (C) valproic acid (VPA)-treated group, (D) VPA-treated and treadmill exercise group. The data are represented as the mean \pm SEM. Symbols a, b, c represent statistical significance $(P<0.05)$ in each group.

present result indicated that neurogenesis in the hippocampal dentate gyrus was lower in the VPA-treated group compared to the control group $(P<0.05)$. In contrast, treadmill exercise increased neurogenesis in the VPA-injected rats $(P<0.05)$.

\section{Effect of treadmill exercise on the co-localization of reelin in the hippocampus}

Reelin protein was expressed in the CA1, CA3, hilus, and dentate gyrus in the hippocampus. Co-localization of reelin with BrdUpositive cells was observed in the hippocampal dentate gyrus (Fig. 4). Reelin expression in the hippocampus was lower in the VPAtreated group compared to the control group. Treadmill exercise increased reelin expressions in the VPA-injected rats.

\section{Effect of treadmill exercise on the expressions of reelin and its down-stream molecules in the hippocampus}

BrdU-positive neurons were co-localized with reelin in the dentate gyrus of the hippocampus (Fig. 5, upper). The effect of treadmill exercise on the expressions of reelin and its down-stream molecules, PI3K, p-Akt, and p-ERK1/2, is presented in Fig. 5 (lower). Band intensity of each protein expressed in control group was set at 1.00 .

When the level of reelin in the control group was set at $1.0 \pm 0$, the level of reelin was $1.1 \pm 0.02$ in the control and treadmill exer- cise group, $0.3 \pm 0.04$ in the VPA-treated group, and $0.5 \pm 0.06$ in the VPA-treated and treadmill exercise group. When the level of $\mathrm{PI} 3 \mathrm{~K}$ in the control group was set at $1.0 \pm 0$, the level of PI3K was $1.7 \pm 0.15$ in the control and treadmill exercise group, $0.4 \pm$ 0.04 in the VPA-treated group, and $0.7 \pm 0.06$ in the VPA-treated and treadmill exercise group. When the level of p-Akt in the control group was set at $1.0 \pm 0$, the level of p-Akt was $1.3 \pm 0.10$ in the control and treadmill exercise group, $0.5 \pm 0.04$ in the VPAtreated group, and $0.9 \pm 0.04$ in the VPA-treated and treadmill exercise group.

When the level of phosphorylated (p-ERK1/2) in the control group was set at $1.0 \pm 0$, the level of $\mathrm{p}-\mathrm{ERK} 1 / 2$ was $1.9 \pm 0.25$ in the control and treadmill exercise group, $0.2 \pm 0.03$ in the VPAtreated group, and $0.6 \pm 0.06$ in the VPA-treated and treadmill exercise group. The present result indicated that the expressions of reelin and its down-stream molecules, PI3K, p-Akt, and p-ERK1/2, were decreased in the VPA-treated group compared to the control group $(P<0.05)$. In contrast, treadmill exercise increased the expressions of reelin and its down-stream molecules in the VPA-injected rats $(P<0.05)$.

\section{DISCUSSION}

In the present study, we used $400 \mathrm{mg} / \mathrm{kg}$ of VPA to induce au- 


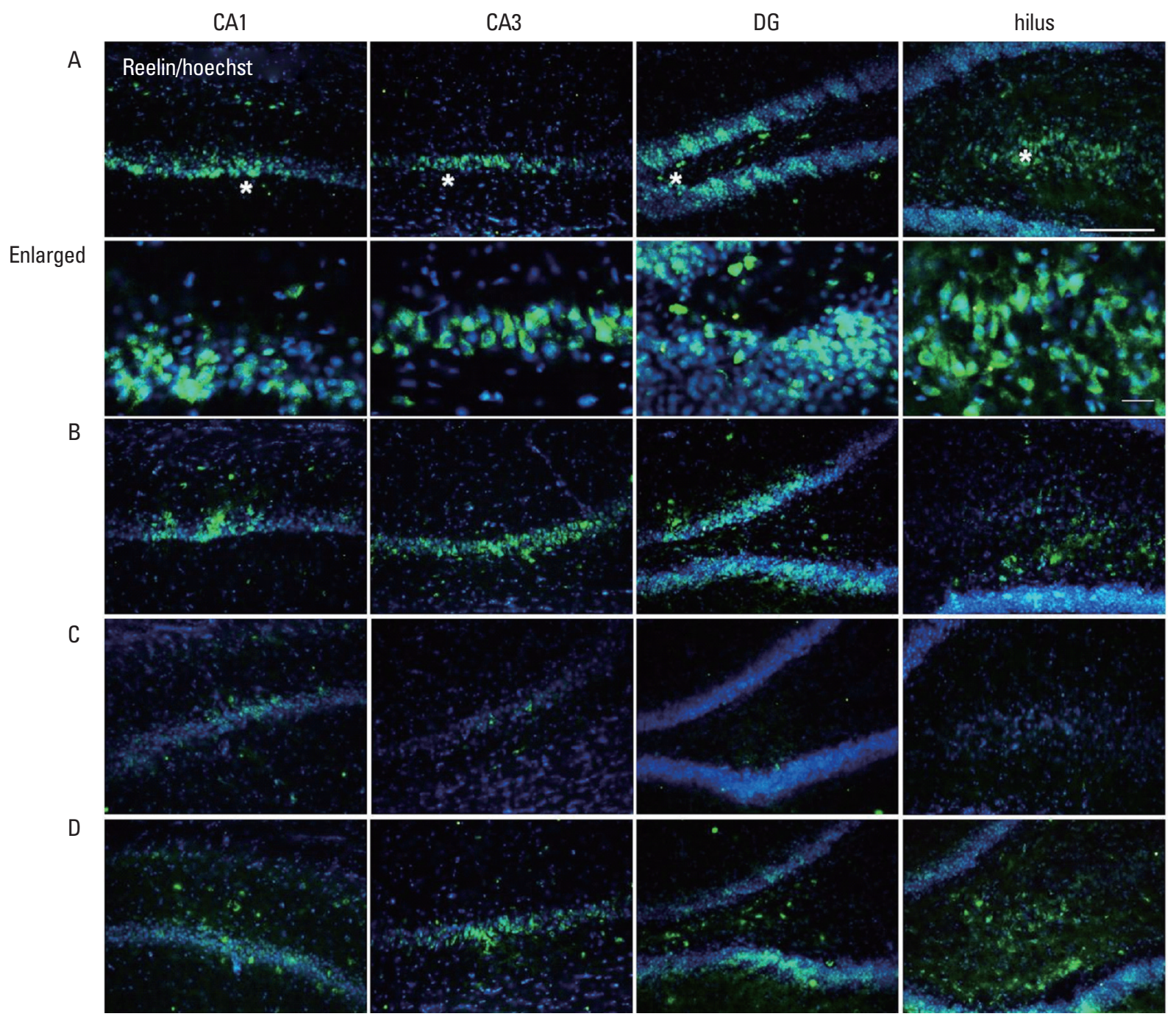

Fig. 4. Photomicrographs of reelin expressions in the CA1, CA3, hilus, and dentate gyrus of the hippocampus. The scale bar represents $100 \mu \mathrm{m}$. (A) Control group, (B) control and exercise group, (C) valproic acid (VPA)-treated group, (D) VPA-treated and treadmill exercise group. Enlarged images are to magnify the asterisk area in photo $A$. The scale bar represents $100 \mu \mathrm{m}$.

tistic symptoms in the rats on the postnatal day 14 , and we observed caspase- 3 activation in the hippocampal dentate gyrus one day after VPA exposure. VPA is primarily used for the treatment of epilepsy, major depression, and bipolar disorder. However, exposure of VPA during pregnancy results in a fetal valporate syndrome similar to autism (Arnon et al., 2000; Mawer et al., 2002). Administration of VPA to the rats on the postnatal day 14 showed autism-like symptoms including impairment of social and cognition and restricted-repetitive behavior (Yochum et al., 2008). Many previous studies reported that less than $500 \mathrm{mg} / \mathrm{kg}$ VPA injection induced severe autism-like state without death of experimental animals (Markram et al., 2008; Yochum et al., 2010). In the present results, the dose of $400 \mathrm{mg} / \mathrm{kg}$ valproic acid was relevant to the inducing autism in the rats.

In the present results, treadmill exercise suppressed VPA-induced aggressive behavior, in contrast treadmill exercise exerted no significant effect on VPA-induced hyperacitivity and non-aggressive behavior. The present results also showed that treadmill exercise alleviated VPA-induced decrement of correct number, in contrast, treadmill exercise exerted no significant effect on time and error number. Our preset study revealed that treadmill exercise alleviated aggressive tendency and improved correct decision in the spatial learning memory in the autistic rats.

It is well documented that physical exercise enhances cognitive function, learning ability, and memory function (Baek et al., 2012; Brisswalter et al., 2002; Kim et al., 2010, 2012). Exercise amelio- 

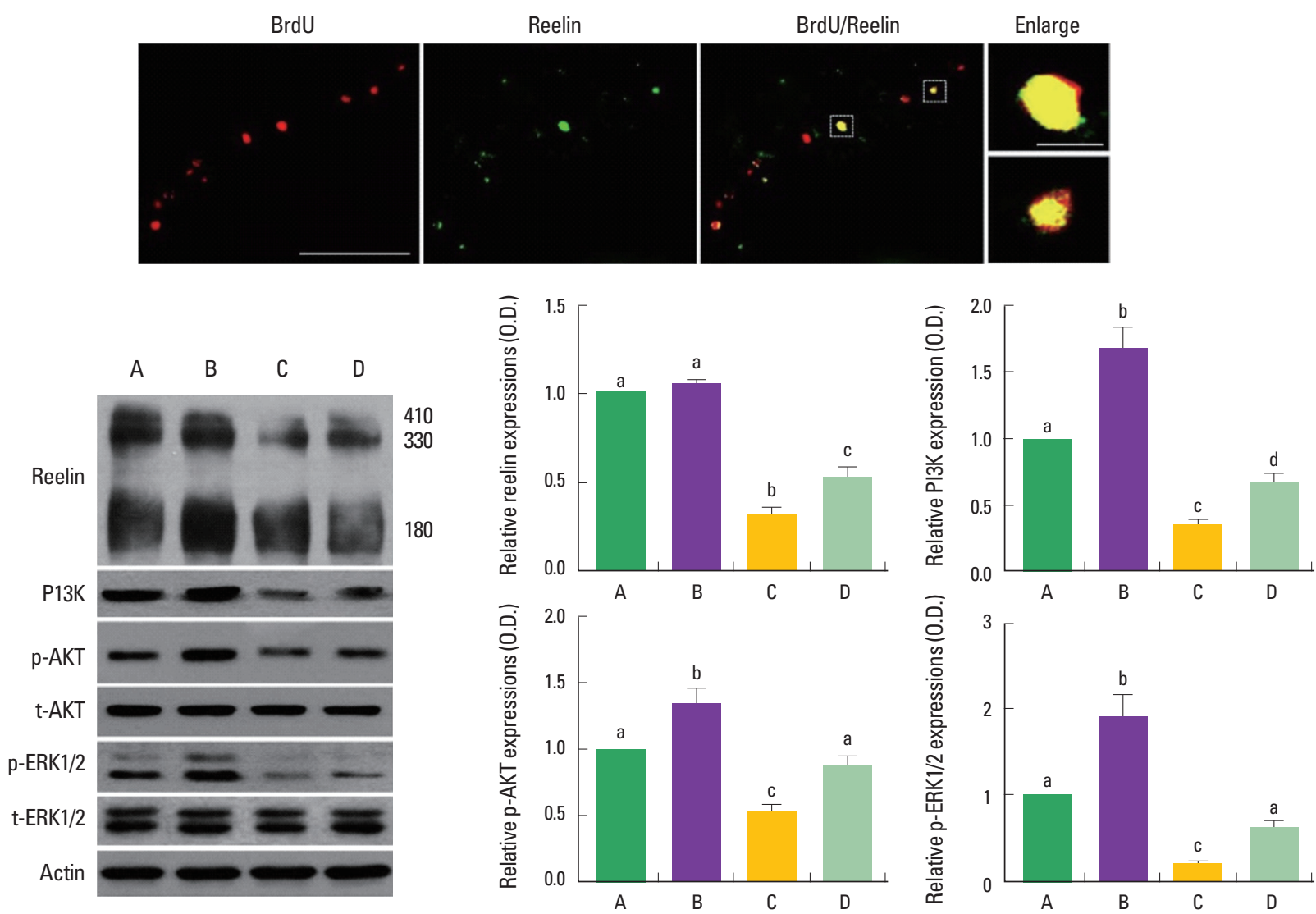

Fig. 5. Effect of treadmill exercise on the activation of reelin signaling pathway in the hippocampus. Upper: Photomicrographys of reelin expression and 5-bromo-2'-deoxyuridine (BrdU)-positive cells in the hippocampal dentate gyrus. The scale bar represents $50 \mu \mathrm{m}$ (left) and $10 \mu \mathrm{m}$ (right). Lower: Western blot analysis of reelin, phosphatidylinositol-3-kinase (PI3K), phosphorylated Akt (p-Akt), and phosphorylated extracellular signal-regulated protein kinase 1 and 2 (p-ERK1/2) in the hippocampus. (A) Control group, (B) control and exercise group, (C) valproic acid (VPA)-treated group, (D) VPA-treated and treadmill exercise group. The data are represented as the mean \pm SEM. Symbols a, b, c represent statistical significance $(P<0.05)$ in each group.

rates memory deficits, improves social behavior problems, and relieves hyperactivity in autism (Allison et al., 1991; Bahrami et al., 2012; Petrus et al., 2008). Following bouts of physical activity, children with autism experienced the decrement in negative behaviors, such as stereotypy, and the increment in positive behaviors, such as time on task (Levinson and Reid, 1993; Lang et al., 2010). Petrus et al. (2008) suggested that exercise provides reduction of stereotypic behaviors in the children with autism spectrum disorder. Children with autism are more inactive in physical activity compared to their peers without autism (Macdonald et al., 2011).

In the present study, we carried out BrdU assay to investigate the level of neurogenesis in the hippocampus of autistic rats. The present results showed that neurogenesis in the hippocampal dentate gyrus was decreased in the autistic rats, in contrast, treadmill exercise increased neurogenesis in the autistic rats.

Individuals with autism in all age-group showed increment in neuronal cell packing density and decrement in nerve cell size in the amygdale, cortex, anterior cingulated gyrus, medial septal nucleus and, hippocampal complex (Bauman and Kemper, 1985; Raymond et al., 1996). In the previous study, the number of BrdUpositive cells in the hippocampal dentate dyrus was suppressed in the VPA-treated autistic rats (Meng et al., 2011). Continuous neurogenesis in the hippocampus contributes to the recovery of autism-like symptoms in rats (Teixeira et al., 2012).

In the present results, reelin expression in the hippocampus was suppressed in the autistic rats, in contrast, treadmill exercise enhanced reelin expression in the autistic rats.

Several factors such as schizophrenia-1 (DISC-1), cyclin-dependent kinase 5 (cdk5), NeuroD, Prox1, and reelin are implicated in the controlling of neurogenesis in the adult dentate granule cells (Gao et al., 2009; Karalay et al., 2011). Of them, reelin is essential for neuronal survival and differentiation. Reelin is an extracel- 
lular protein that is essential for neuronal migration and brain development (Fatemi et al., 2001; Fatemi, 2005). Dysregulation of reelin may be responsible for some of the brain structural and behavioral abnormalities observed in autism (Fatemi et al., 2001). In the adult brain, reelin is involved in the signaling pathway which underlies neurotransmission, memory formation, and synaptic plasticity (Fatemi, 2005). The activation of reelin signaling may inhibit excitotoxic neurotransmission and Tau phosphorylation, and may activate neurogenesis. This may lead to diminished brain injury and to increased brain injury repair (Delahaye et al., 2007).

In the present study, we confirmed the changes of down-stream molecules of the reelin signaling pathway in the autistic rats. Expressions of $\mathrm{PI} 3 \mathrm{~K}$, p-Akt, and p-ERK1/2 in the hippocampus were decreased in the autistic rats, in contrast, treadmill exercise increased the expression of PI3K, p-Akt, and p-ERK1/2 in the autistic rats.

PI3K-Akt signaling pathway is under the control of reelin signaling (Jossin and Goffinet, 2007; Waite and Eickholt, 2010). The relation of PI3K-Akt pathway with autism spectrum disorders has been suggested. Kwon et al. (2006) reported that abnormal activation of the PI3K-Akt pathway might be the one of the underlying mechanisms of macrocephaly and behavioral abnormalities in human autism spectrum disorders. PI3K signaling pathway is involved in the development of the brain, and aberrant $\mathrm{PI} 3 \mathrm{~K}$ signaling is an important contributing factor to the pathophysiology of disorders such as schizophrenia and autism (Waite and Eickholt, 2010). Weaken PI3K-Akt-Bcl-xL results in an augmented cell death, in contrast, activation of PI3K-Akt signaling pathway increases cell survival (Jeon et al., 2011).

In the present study, treadmill exercise ameliorated aggressive behavior and improved spatial learning memory through activation of reeling signaling pathway in the VPA-induced autistic rats. The present study suggests the possibility that exercise can be applied for the symptom relief of autistic patients.

\section{CONFLICT OF INTEREST}

No potential conflict of interest relevant to this article was reported.

\section{ACKNOWLEDGMENTS}

This work was supported by the National Research Foundation of Korea Grant founded by the Korean Government (NRF-2010327-G00101).

\section{REFERENCES}

Allison DB, Basile VC, MacDonald RB. Brief report: comparative effects of antecedent exercise and lorazepam on the aggressive behavior of an autistic man. J Autism Dev Disord 1991;21:89-94.

Arnon J, Shechtman S, Ornoy A. The use of psychiatric drugs in pregnancy and lactation. Isr J Psychiatry Relat Sci 2000;37:205-222.

Baek SS, Jun TW, Kim KJ, Shin MS, Kang SY, Kim CJ. Effects of postnatal treadmill exercise on apoptotic neuronal cell death and cell proliferation of maternal-separated rat pups. Brain Dev 2012;34:45-56.

Bahrami F, Movahedi A, Marandi SM, Abedi A. Kata techniques training consistently decreases stereotypy in children with autism spectrum disorder. Res Dev Disabil 2012;33:1183-1193.

Bauman M, Kemper TL. Histoanatomic observations of the brain in early infantile autism. Neurology 1985; 35:866-874.

Beffert U, Morfini G, Bock HH, Reyna H, Brady ST, Herz J (2002). Reelinmediated signaling locally regulates protein kinase B/Akt and glycogen synthase kinase 3beta. J Biol Chem 2002;277:49958-49964.

Beffert U, Weeber EJ, Durudas A, Qiu S, Masiulis I, Sweatt JD, Li WP, Adelmann G, Frotscher M, Hammer RE, Herz J. Modulation of synaptic plasticity and memory by Reelin involves differential splicing of the lipoprotein receptor Apoer2. Neuron 2005;47:567-579.

Brisswalter J, Collardeau M, René A. Effects of acute physical exercise characteristics on cognitive performance. Sports Med 2002;32:555-566.

Cohen GM. Caspases: the executioners of apoptosis. Biochem J 1997;326: 1-16.

Cotman CW, Berchtold NC, Christie LA. Exercise builds brain health: key roles of growth factor cascades and inflammation. Trends Neurosci 2007;30:464-472.

Delahaye NF, Coltel N, Puthier D, Barbier M, Benech P, Joly F, Iraqi FA, Grau GE, Nguyen C, Rihet P. Gene expression analysis reveals early changes in several molecular pathways in cerebral malaria-susceptible mice versus cerebral malaria-resistant mice. BMC Genomics 2007;8: 452:1-16

Fatemi SH. Reelin glycoprotein: structure, biology and roles in health and disease. Mol Psychiatry 2005;10:251-257.

Fatemi SH, Pearce DA, Brooks AI, Sidwell RW. Prenatal viral infection in mouse causes differential expression of genes in brains of mouse progeny: a potential animal model for schizophrenia and autism. Synapse 2005;57:91-99

Fatemi SH, Stary JM, Halt AR, Realmuto GR. Dysregulation of Reelin and Bcl-2 proteins in autistic cerebellum. J Autism Dev Disord 2001;31:529535.

Gao Z, Ure K, Ables JL, Lagace DC, Nave KA, Goebbels S, Eisch AJ, Hsieh J. Neurod1 is essential for the survival and maturation of adult-born 
neurons. Nat Neurosci 2009;12:1090-1092.

Jeon SJ, Seo JE, Yang SI, Choi JW, Wells D, Shin CY, Ko KH. Cellular stressinduced up-regulation of FMRP promotes cell survival by modulating PI3K-Akt phosphorylation cascades. Cellular stress-induced up-regulation of FMRP promotes cell survival by modulating PI3K-Akt phosphorylation cascades. J Biomed Sci 2011;18:17.

Jossin Y, Goffinet AM. Reelin signals through phosphatidylinositol 3-kinase and Akt to control cortical development and through mTor to regulate dendritic growth. Mol Cell Biol 2007;27:7113-7124.

Karalay O, Doberauer K, Vadodaria KC, Knobloch M, Berti L, Miquelajauregui A, Schwark M, Jagasia R, Taketo MM, Tarabykin V, Lie DC, Jessberger S. Prospero-related homeobox 1 gene (Prox1) is regulated by canonical Wnt signaling and has a stage-specific role in adult hippocampal neurogenesis. Proc Natl Acad Sci U S A 2011;108:5807-5812.

Kim BK, Shin MS, Lee HH, Sung YH, Kim H. Swimming alleviates streptozotocin-induced short-term memory impairment in rats. Kor J Exer Rehabil 2012;8:273-284.

Kim H, Heo HI, Kim DH, Ko IG, Lee SS, Kim SE, Kim BK, Kim TW, Ji ES, Kim JD, Shin MS, Choi YW, Kim CJ. Treadmill exercise and methylphenidate ameliorate symptoms of attention deficit/hyperactivity disorder through enhancing dopamine synthesis and brain-derived neurotrophic factor expression in spontaneous hypertensive rats. Neurosci Lett 2011;504: 35-39.

Kim SE, Ko IG, Kim BK, Shin MS, Cho S, Kim CJ, Kim SH, Baek SS, Lee EK, Jee YS. Treadmill exercise prevents aging-induced failure of memory through an increase in neurogenesis and suppression of apoptosis in rat hippocampus. Exp Gerotol 2010;45:357-365.

Kuhn HG, Biebl M, Wilhelm D, Li M, Friedlander RM, Winkler J. Increased generation of granule cells in adult Bcl-2-overexpressing mice: a role for cell death during continued hippocampal neurogenesis. Eur J Neurosci 2005;22:1907-1915.

Kwon CH, Luikart BW, Powell CM, Zhou J, Matheny SA, Zhang W, Li Y, Baker SJ, Parada LF. Pten regulates neuronal arborization and social interaction in mice. Neuron 2006;50:377-388.

Lang R, Koegel LK, Ashbaugh K, Regester A, Ence W, Smith W. Physical exercise and children with autism spectrum disorders: A systematic review. Res Autism Spectr Disord 2010;4:565-576.

Levinson LJ, Reid G: The effects of exercise intensity on the stereotypic behaviors of individuals with autism. Adapt Phys Activ Q 1993;10: 255-268.

Macdonald M, Esposito P, Ulrich D. The physical activity patterns of children with autism. BMC Res Notes 2011;4:422.

Markram K, Rinaldi T, La Mendola D, Sandi C, Markram H. Abnormal fear conditioning and amygdala processing in an animal model of au- tism. Neuropsychopharmacology 2008;33:901-12.

Mawer G, Clayton-Smith J, Coyle H, Kini U. Outcome of pregnancy in women attending an outpatient epilepsy clinic: adverse features associated with higher doses of sodium valproate. Seizure 2002;11:512-518.

Meng L, Lu L, Murphy KM, Yuede CM, Cheverud JM, Csernansky JG, Dong $\mathrm{H}$. Neuroanatomic and behavioral traits for autistic disorders in age-specific restricted index selection mice. Neuroscience 2011;189: 215-222.

Nuñez G, Benedict MA, Hu Y, Inohara N. 1998. Caspases: the proteases of the apoptotic pathway. Oncogene 1998;17:3237-3245.

Penn HE. Neurobiological correlates of autism: a review of recent research. Child Neuropsychol 2006;12:57-79.

Petrus C, Adamson SR, Block L, Einarson SJ, Sharifnejad M, Harris SR. Effects of exercise interventions on stereotypic behaviours in children with autism spectrum disorder. Physiother Can 2008;60:134-145.

Raymond GV, Bauman ML, Kemper TL. Hippocampus in autism: a Golgi analysis. Acta Neuropathol 1996;91:117-119.

Rogers SJ. What are infant siblings teaching us about autism in infancy? Autism Res 2009;2:125-137.

Seo JH, Kim TW, Kim CJ, Sung YH, Lee SJ. Treadmill exercise during pregnancy ameliorates post-traumatic stress disorder-induced anxiety-like responses in maternal rats. Mol Med Report 2013;7:389-395.

Teixeira CM, Kron MM, Masachs N, Zhang H, Lagace DC, Martinez A, Reillo I, Duan X, Bosch C, Pujadas L, Brunso L, Song H, Eisch AJ, Borrell V, Howell BW, Parent JM, Soriano E. Cell-autonomous inactivation of the reelin pathway impairs adult neurogenesis in the hippocampus. J Neurosci 2012;32:12051-12065.

Thompson CB. Apoptosis in the pathogenesis and treatment of disease. Science 1995;267:1456-62.

Vernazza-Martin S, Martin N, Vernazza A, Lepellec-Muller A, Rufo M, Massion J, Assaiante C. Goal directed locomotion and balance control in autistic children. J Autism Dev Disord 2005;35:91-102.

Wagner GC, Reuhl KR, Cheh M, McRae P, Halladay AK. A new neurobehavioral model of autism in mice: pre- and postnatal exposure to sodium valproate. J Autism Dev Disord 2006;36:779-793.

Waite K, Eickholt BJ. The neurodevelopmental implications of PI3K signaling. Curr Top Microbiol Immunol 2010;346:245-265.

Yochum CL, Bhattacharya P, Patti L, Mirochnitchenko O, Wagner GC. Animal model of autism using GSTM1 knockout mice and early post-natal sodium valproate treatment. Behav Brain Res 2010;210:202-210.

Yochum CL, Dowling P, Reuhl KR, Wagner GC, Ming X. VPA-induced apoptosis and behavioral deficits in neonatal mice. Brain Res 2008;1203: 126-132. 